\title{
BIFURCATION ANALYSIS OF EQUILIBRIUM POINT IN TWO NODE POWER SYSTEM
}

\author{
Halima Aloui, Faouzi Bacha and Moncef Gasmi \\ Department of Physics and Instrumentation Engineering, \\ National Institue of Applied Sciences and Technology (INSAT) Centre Urbain Nord, BP 676, 1080 Tunis Cedex, Tunisie
}

Received 2013-01-04; Revised 2013-08-17; Accepted 2014-01-29

\begin{abstract}
This study presents a study of bifurcation in a dynamic power system model. It becomes one of the major precautions for electricity suppliers and these systems must maintain a steady state in the neighborhood of the operating points. We study in this study the dynamic stability of two node power systems theory and the stability of limit cycles emerging from a subcritical or supercritical Hopf bifurcation by computing the first Lyapunov coefficient. The MATCONT package of MATLAB was used for this study and detailed numerical simulations presented to illustrate the types of dynamic behavior. Results have proved the analyses for the model exhibit dynamical bifurcations, including Hopf bifurcations, Limit point bifurcations, Zero Hopf bifurcations and Bagdanov-taknes bifurcations.
\end{abstract}

Keywords:Power System Stability, Hopf Bifurcations, Limit Point Bifurcations, Bagdanov-Taknes Bifurcations

\section{INTRODUCTION}

Voltage control and stability problems in the transient regimes are becoming one of the most important issues in the power system due the intensive use of the transmission network (Avalos et al., 2009; Echavarren et al., 2009). Voltage stability is defined by the capacity of the power system to maintain acceptable voltages at all nodes in the system under normal condition and after being subject to a disturbance (Abro and Mohamad-Saleh, 2012; Subramani et al., 2012).

The dynamic of this power system are generally described by the following Ordinary Differential Equations (ODE) Equation (1):

$\dot{\mathrm{x}}=\mathrm{f}(\mathrm{x}, \alpha)$

where, $\mathrm{x} \in \mathrm{R}^{\mathrm{n}}$ corresponds to the state variables, $\alpha \in \mathrm{R}$ is the bifurcation parameter. In a power system literature, the package Matcont based on the continuation method and applied to analyse the voltage collapse. The study of the continuation of equilibrium point in a two node power system demonstrated the existence of a Hopf
Bifurcation point.

The Hopf Bifurcation generates a limit cycles which are stable if it is supercritical or unstable if it is subcritical, the limit cycle is asymptotically stable if all other Floquet multipliers lay within the unit circle.

The continuation method demonstrated also the limit point bifurcations characterized by its period and Normal form coefficient.

We can study the influence of the variation by the parameters of the Automatic Voltage Regulator (AVR).

The concept of two node power system is applied to simplify the mathematical model of power system. A brief review of bifurcation theory is used to investigate this study and several important simulations results are presented.

\section{MATERIALS AND METHODS}

The configuration of the power system presented in this study can be described by Fig. 1. The power system model consists of two bus which is composed by a synchronous machine connected to a load modeled with active and reactive power components $\mathrm{P}_{1}+\mathrm{jQ}$, a transformer and a AVR, as cited in (JiaKuan and Xin, 2007).

Corresponding Author: Halima Aloui, Department of Physics and Instrumentation Engineering, National Institue of Applied Sciences and Technology (INSAT) Centre Urbain Nord, BP 676, 1080 Tunis Cedex, Tunisie 


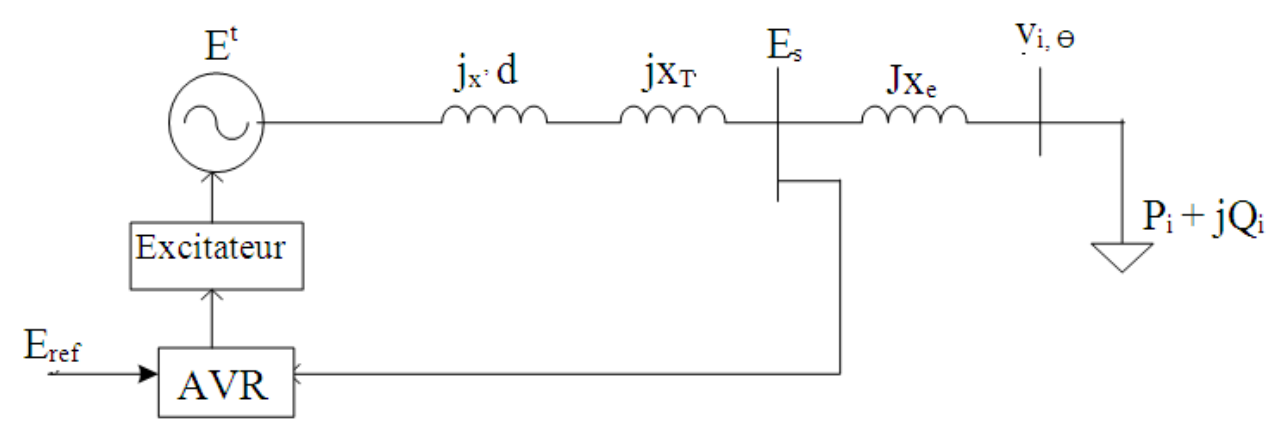

Fig. 1. Power system model for two bus

The Voltage equations including the transient variation of machine flux linkages using a two-axis referential frame can be written as Equation (2):

$$
\left\{\begin{array}{l}
\dot{\mathrm{E}}_{\mathrm{d}}^{\prime}=\left(-\mathrm{E}_{\mathrm{d}}^{\prime}+\left(\mathrm{x}_{\mathrm{q}}-\mathrm{x}_{\mathrm{d}}^{\prime}\right) \mathrm{I}_{\mathrm{q}}\right) / \mathrm{T}_{\mathrm{q} 0}^{\prime} \\
\dot{\mathrm{E}}_{\mathrm{q}}^{\prime}=\left(-\mathrm{E}_{\mathrm{q}}^{\prime}-\left(\mathrm{x}_{\mathrm{d}}-\mathrm{x}_{\mathrm{d}}^{\prime}\right) \mathrm{I}_{\mathrm{d}}+\mathrm{E}_{\mathrm{fd}}\right) / \mathrm{T}_{\mathrm{d} 0}^{\prime}
\end{array}\right.
$$

\section{Where:}

$\mathrm{E}_{\mathrm{d}}$ and $\mathrm{E}_{\mathrm{q}}=$ Respectively the direct and the quadrature transient voltages

$\mathrm{I}_{\mathrm{d}}$ and $\mathrm{I}_{\mathrm{q}} \quad=$ Respectively the direct and the quadrature currents

$\mathrm{T}_{\mathrm{d} 0}$ and $\mathrm{T}_{\mathrm{q} 0}=$ The open circuit time constants

$\mathrm{x}_{\mathrm{d}}$ and $\mathrm{x}_{\mathrm{d}}{ }=$ Respectively the synchronous and the transient reactance in d-axe

$\mathrm{x}_{\mathrm{q}} \quad=$ The synchronous reactance in $\mathrm{q}$-axe

$\mathrm{E}_{\mathrm{fd}} \quad=$ The field voltage.

The d-q components of the synchronous machine current are defined by Equation (3):

$\left\{\begin{array}{l}\mathrm{I}_{\mathrm{q}}=\left(-\mathrm{E}_{\mathrm{d}}^{\prime}+\mathrm{V}_{1} \sin (\delta-\theta)\right) / \mathrm{x}_{\mathrm{E}} \\ \mathrm{I}_{\mathrm{d}}=\left(\mathrm{E}_{\mathrm{q}}^{\prime}-\mathrm{V}_{1} \cos (\delta-\theta)\right) / \mathrm{x}_{\mathrm{E}}\end{array}\right.$

Where:

$$
\mathrm{x}_{\mathrm{E}}=\mathrm{x}_{\mathrm{d}}^{\prime}+\mathrm{x}_{\mathrm{T}}+\mathrm{x}_{\mathrm{e}}
$$

$\mathrm{x}_{\mathrm{T}}$ and $\mathrm{x}_{\mathrm{e}}$ are respectively step-up transformer reactance and transmission line reactance $V_{1}$ and $\theta$ are respectively the magnitude and the angle of the load bus voltage.

The algebraic equations are written by Equation (4):
$\left\{\begin{array}{l}-\mathrm{E}_{\mathrm{d}}^{\prime} \cos \delta+\mathrm{E}_{\mathrm{q}}^{\prime} \sin \delta-\mathrm{V}_{1} \sin \theta-\frac{\mathrm{X}_{\mathrm{E}}}{\mathrm{V}_{\mathrm{l}}}\left(\mathrm{P}_{1} \cos \theta+\mathrm{Q}_{1} \sin \theta\right)=0 \\ \mathrm{E}_{\mathrm{d}}^{\prime} \sin \delta+\mathrm{E}_{\mathrm{q}}^{\prime} \cos \delta-\mathrm{V}_{1} \cos \theta-\frac{\mathrm{X}_{\mathrm{E}}}{\mathrm{V}_{\mathrm{l}}}\left(-\mathrm{P}_{1} \sin \theta+\mathrm{Q}_{1} \cos \theta\right)=0\end{array}\right.$

Through the analysis above, we can re-write the Equation (4) as Equation (5):

$$
\begin{aligned}
& \xi \dot{\mathrm{V}}_{1}=-\mathrm{E}_{\mathrm{d}}^{\prime} \cos \delta+\mathrm{E}_{\mathrm{q}}^{\prime} \sin \delta-\mathrm{V}_{1} \sin \theta-\frac{\mathrm{X}_{\mathrm{E}}}{\mathrm{V}_{1}}\left(\mathrm{P}_{1} \cos \theta+\mathrm{Q}_{1} \sin \theta\right) \\
& +\mathrm{E}_{\mathrm{d}}^{\prime} \sin \delta+\mathrm{E}_{\mathrm{q}}^{\prime} \cos \delta-\mathrm{V}_{1} \cos \theta-\frac{\mathrm{XE}_{\mathrm{E}}}{\mathrm{V}_{1}}\left(-\mathrm{P}_{1} \sin \theta+\mathrm{Q}_{1} \cos \theta\right)
\end{aligned}
$$

Where:

$\delta=$ The rotor angle.

To make the system $(2,4)$ have the same behaviour as system $(2,5)$, a very small singular factor $\mathrm{x}$ is introduced. Where we select $\mathrm{x}=0.0001$ When $\mathrm{x}$ is small enough, systems $(2,4)$ and $(2,5)$ are expected to have similar system behaviours (JiaKuan and Xin, 2007).

The excitation for the generator is given by the output of the AVR given by the diagram in Fig. 2.

The AVR-model is given by Equation (6):

$$
\left\{\begin{array}{l}
\mathrm{T}_{\mathrm{A}} \dot{\mathrm{V}}_{\mathrm{R}}=-\mathrm{V}_{\mathrm{R}}+\mathrm{K}_{\mathrm{A}}\left(\mathrm{E}_{\mathrm{ref}}-\mathrm{E}_{\mathrm{s}}-\left(\mathrm{K}_{\mathrm{f}} \mathrm{E}_{\mathrm{fd}} / \mathrm{T}_{\mathrm{f}}\right)+\mathrm{R}_{\mathrm{f}}\right) \\
\mathrm{T}_{\mathrm{E}_{\mathrm{fd}}} \dot{\mathrm{E}}_{\mathrm{fd}}=-\mathrm{E}_{\mathrm{fd}}+\mathrm{V}_{\mathrm{R}} \mathrm{T}_{\mathrm{f}} \dot{\mathrm{R}}_{\mathrm{f}}=-\mathrm{R}_{\mathrm{f}}+\mathrm{K}_{\mathrm{f}} \mathrm{E}_{\mathrm{fd}} / \mathrm{T}_{\mathrm{f}}
\end{array}\right.
$$

Where:

$\mathrm{V}_{\mathrm{R}} \quad=$ The voltage regulator

$\mathrm{T}_{\mathrm{A}} \quad=$ The time constant

$\mathrm{K}_{\mathrm{A}} \quad=$ The gain

$\mathrm{T}_{\mathrm{E}}$ and $\mathrm{E}_{\mathrm{fd}}=$ Respectively the exciter time constant and the reference voltage set point

$\mathrm{R}_{\mathrm{f}}$ and $\mathrm{T}_{\mathrm{f}}=$ Respectively the state and the time constant

$\mathrm{K}_{\mathrm{f}} \quad=$ The gain of stabilizing feedback loop 


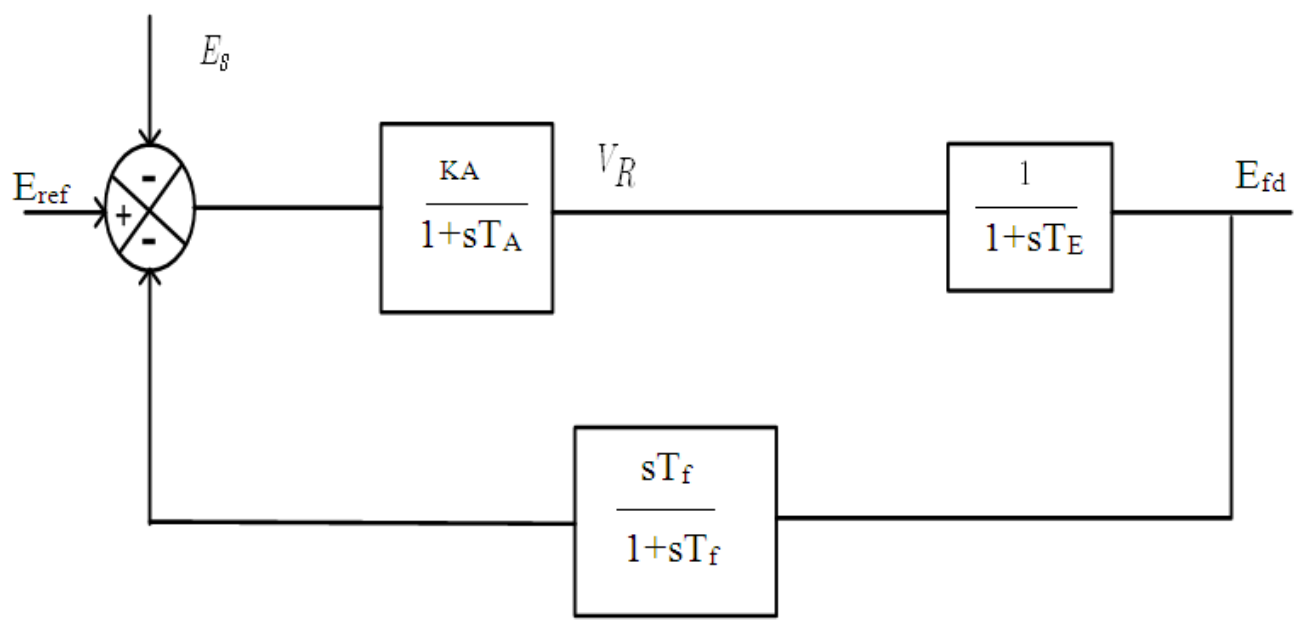

Fig. 2. Structure of a DC1 regulator

Hence, our system has six nonlinear differential equations so as his model is given by the following system of Equation (7):

$$
\left\{\begin{array}{l}
\dot{\mathrm{E}}_{\mathrm{d}}^{\prime}=\left(-\mathrm{E}_{\mathrm{d}}^{\prime}+\left(\mathrm{x}_{\mathrm{q}}-\mathrm{x}_{\mathrm{d}}^{\prime}\right) \mathrm{I}_{\mathrm{q}}\right) / \mathrm{T}_{\mathrm{q} 0}^{\prime} \\
\dot{\mathrm{E}}_{\mathrm{q}}^{\prime}=\left(-\mathrm{E}_{\mathrm{q}}^{\prime}-\left(\mathrm{x}_{\mathrm{d}}-\mathrm{x}_{\mathrm{d}}^{\prime}\right) \mathrm{I}_{\mathrm{d}}+\mathrm{E}_{\mathrm{fd}}\right) / \mathrm{T}_{\mathrm{d} 0}^{\prime} \\
\dot{\mathrm{V}}_{\mathrm{R}}=\left(-\mathrm{V}_{\mathrm{R}}+\mathrm{K}_{\mathrm{A}}\left(\mathrm{E}_{\mathrm{ref}}-\mathrm{E}_{\mathrm{s}}-\left(\mathrm{K}_{\mathrm{f}} \mathrm{E}_{\mathrm{fd}} / \mathrm{T}_{\mathrm{f}}\right)+\mathrm{R}_{\mathrm{f}}\right)\right) / \mathrm{T}_{\mathrm{A}} \\
\dot{\mathrm{E}}_{\mathrm{fd}}=\left(-\mathrm{E}_{\mathrm{fd}}+\mathrm{V}_{\mathrm{R}}\right) / \mathrm{T}_{\mathrm{E}} \\
\dot{\mathrm{R}}_{\mathrm{f}}=\left(-\mathrm{R}_{\mathrm{f}}+\mathrm{K}_{\mathrm{f}} \mathrm{E}_{\mathrm{fd}} / \mathrm{T}_{\mathrm{f}}\right) / \mathrm{T}_{\mathrm{f}} \\
\dot{\mathrm{V}}_{\mathrm{l}}=\left(-\mathrm{E}_{\mathrm{d}}^{\prime} \cos \delta+\mathrm{E}_{\mathrm{q}}^{\prime} \sin \delta-\mathrm{V}_{1} \sin \theta-\frac{\mathrm{x}_{\mathrm{E}}}{\mathrm{V}_{\mathrm{l}}}\left(\mathrm{P}_{1} \cos \theta+\mathrm{Q}_{1} \sin \theta\right)\right. \\
\left.+\mathrm{E}_{\mathrm{d}}^{\prime} \sin \delta+\mathrm{E}_{\mathrm{q}}^{\prime} \cos \delta-\mathrm{V}_{\mathrm{l}} \cos \theta-\frac{\mathrm{x}_{\mathrm{E}}}{\mathrm{V}_{\mathrm{l}}}\left(-\mathrm{P}_{\mathrm{l}} \sin \theta+\mathrm{Q}_{\mathrm{l}} \cos \theta\right)\right) / \xi
\end{array}\right.
$$

We consider the vector of the variables state $X=\left[\mathrm{E}_{\mathrm{d}}{ }_{\mathrm{d}}\right.$ $E_{\mathrm{q}}^{\prime} \mathrm{V}_{\mathrm{R}} \mathrm{E}_{\mathrm{fd}} \mathrm{R}_{\mathrm{f}} \mathrm{V}_{\mathrm{l}}$ ] and $\alpha=\mathrm{P}_{\mathrm{l}}$ is the bifurcation parameter.

\subsection{A Brief Review of Bifurcation Theory}

The voltage stability is a non-linear phenomenon and it is natural to use non-linear method to study the parameters that it is very slowly and predicts how a power system becomes unstable.

\subsection{The Hopf bifurcation}

At this point, there is an emergence of oscillatory instability, two complex conjugate eigenvalues cross the imaginary axis (Jazaeri and Khatibi, 2008). The nature Hopf bifurcation (supercritical or subcritical) is determinate by the sign of the first Lyapunov coefficient $l_{1}(0)$ of the dynamical system. The coefficient can be computed as follows: Suppose that the system (1) have as an equilibrium point $\left(\mathrm{x}^{0}, \alpha^{0}\right)$ and $\left[\mathrm{A}_{0}\right]$ the Jacobian matrix which has a distinct pair of complex eigenvalues on the imaginary axis, $\lambda_{1,2}= \pm \mathrm{iw}_{0}$ a good example. $\mathrm{w}_{0}>0$ and these eigenvalues are the only eigenvalues of $\left[\mathrm{A}_{0}\right]$ with zero real parts. The Taylor expansion of $\mathrm{f}\left(\mathrm{x}^{0}, \alpha^{0}\right)$ Equation (8):

$$
\mathrm{f}\left(\mathrm{x}^{0}, \alpha^{0}\right)=\left[\mathrm{A}_{0}\right] \mathrm{x}+1 / 2 \mathrm{~B}(\mathrm{x}, \mathrm{x})+1 / 6 \mathrm{C}(\mathrm{x}, \mathrm{x}, \mathrm{x})+\mathrm{O}\left(\|\mathrm{x}\|^{4}\right)
$$

where, $\mathrm{B}(\mathrm{x}, \mathrm{y})$ and $\mathrm{C}(\mathrm{x}, \mathrm{y})$ are symmetric multi-linear vector functions of $\mathrm{x}, \mathrm{y}, \mathrm{z} \in \mathrm{R}^{\mathrm{n}}$

With components Equation (9 and 10):

$$
\begin{aligned}
& \mathrm{B}_{\mathrm{j}}(\mathrm{x}, \mathrm{y})=\sum_{\mathrm{k}, \mathrm{m}=1}^{\mathrm{n}} \partial^{2} \mathrm{f}_{\mathrm{j}}\left(\xi, \alpha^{0}\right) /\left.\partial \xi_{\mathrm{k}} \partial \xi_{1}\right|_{\xi=0} \mathrm{x}_{\mathrm{k}} \mathrm{y}_{1} \\
& \mathrm{C}_{\mathrm{j}}(\mathrm{x}, \mathrm{y}, \mathrm{z})=\sum_{\mathrm{k}, 1, \mathrm{~m}=1}^{\mathrm{n}} \partial^{2} \mathrm{f}_{\mathrm{j}}\left(\xi, \alpha^{0}\right) /\left.\partial \xi_{\mathrm{k}} \partial \xi_{1} \partial \xi_{\mathrm{m}}\right|_{\xi=0} \mathrm{x}_{\mathrm{k}} \mathrm{y}_{1} \mathrm{z}_{\mathrm{m}}
\end{aligned}
$$

where, $\mathrm{j}=1,2 \ldots n$.

\subsection{Limit Point or Saddle Node Bifurcation (SNB)}

At the saddle node bifurcation the stable and unstable equilibrium points coalesce and disappear then the Jacobian matrix $\mathrm{J}=\partial f / \partial \mathrm{x}$ is singular, thus one of the eigenvalues (or singular variables) must be zero (Fang and Yang, 2012).

\subsection{Limit Cycle}

A cycle is a closed orbit (Ghaffari et al., 2009) corresponding to a periodic solution with period $\mathrm{T}, \mathrm{x}(0)=$ $\mathrm{x}(\mathrm{T})$. By the definition, in a neighborhood of a limit cycle 
they are not other cycles Since $\mathrm{T}$ is not known in advance, it is customary to use an equivalent system defined on the fixed interval $[0,1]$ by rescaling time Equation (11):

$$
\left\{\begin{array}{l}
\mathrm{dx} / \mathrm{dt}-\mathrm{Tf}(\mathrm{x}, \alpha)=0 \\
\mathrm{x}(0)=\mathrm{x}(\mathrm{T})
\end{array}\right.
$$

A phase shifted function $\phi(t)=x(t+s)$ is also a solution of the system (1) for any value of $s$. To obtain a unique solution an extra constraint is needed. The following integral constraint is often used Equation (12):

$$
\int_{0}^{\mathrm{T}} \operatorname{áx}(\mathrm{t}), \dot{\mathrm{x}}_{\text {old }} \tilde{\mathrm{n}} \mathrm{dt}=0
$$

where, $\mathrm{x}_{\mathrm{dd}}$ is the derivative of a previous solution.

The stability of the branch of periodic solution created from the continuation of the Hopf bifurcation is determined by the monodromy matrix Equation (13):

$$
\dot{j}(t)-\operatorname{Tf}_{x}(x(t), \alpha) j(t)=0, j(0)=I_{n}
$$

\subsection{Find Bifurcation of Limit Cycles (Period Doubling PD)}

The period doubling bifurcation is defining by the following Equation (14) (Govaerts et al., 2005):

$$
\left\{\begin{array}{l}
\mathrm{dx} / \mathrm{dt}-\mathrm{Tf}(\mathrm{x}, \alpha)=0 \\
\mathrm{x}(0)-\mathrm{x}(1)=0 \\
\int_{0}^{1}\left\langle\mathrm{x}(\mathrm{t}), \dot{\mathrm{x}}_{\mathrm{old}}\right\rangle \mathrm{dt}=0 \\
\mathrm{G}(\mathrm{x}, \mathrm{T}, \alpha)=0
\end{array}\right.
$$

This is exactly the system defining limit cycles but with one extra constraint $\mathrm{G}(\mathrm{x}, \mathrm{T}, \alpha)=0$.

where, $\mathrm{G}(\mathrm{x}, \mathrm{T}, \alpha)$ is the solution of the following Equation (15):

$$
\left\{\begin{array}{l}
\dot{\mathrm{v}}(\tau)-\mathrm{Tf}_{\mathrm{x}}(\mathrm{x}, \alpha) \mathrm{v}(\tau)+\mathrm{G}_{\varphi}(\tau)=0 \mathrm{v}(0)+\mathrm{v}(1)=0 \\
\int_{0}^{1} \mathrm{a} \psi(\tau), \mathrm{v}(\tau) \tilde{\mathrm{n} d} \tau=1
\end{array}\right.
$$

\subsection{Neimark-Sacker Bifurcation (SN)}

The SN is the birth of the closed invariant curve from a fixed point in dynamical systems with discrete time, when the fixed point changes stability via a pair complex eigenvalues with unit modulus.

\section{RESULTS}

Using the parameters given in Table 1, we will simulate and evaluate the analysis of dynamic voltage stability of two node power system. We show the continuation of the equilibrium point $\mathrm{x}=[0.39649$ $1.010951 .447611 .447640 .055670 .9731]$ and $P_{1}=0.7$.

The results are a Hopf Bifurcation point (labeled by $\mathrm{H})$, two Saddle Node Bifurcation (labeled also by $\mathrm{H}$ ) and a limit point bifurcation (labeled by LP), Fig. 3 .

The detaliled results of each bifurcation point are abstracts in Table 2. We can determine The eigenvalues of the bifurcations points to describe the stability of these points. The eigenvalues summarized in Table $\mathbf{3}$ and schematized by Fig. 4.

\subsection{Continuation of the Hopf Bifurcation}

In the same condition, we draw the continuation in the Hopf point.

Figure 5 indicates the time reponses of the voltage $\mathrm{Vl}$, in the Hopf bifurcation point the system loses its stability and the excitation voltage presented oscillation.

The continuation in Hopf bifurcation represent a limit cycles. So there are parentage of Neimark-Sacker can be represented by Fig. 6, his period equal to 2.615936 and his parameter equal to $8.785358 \mathrm{e}-001$.

Table 1. The Parameters of a Power system model for two bus

\begin{tabular}{ll}
\hline Network parameters & $\mathrm{xT}=0.15 \mathrm{pu}, \mathrm{xe}=0.3406 \mathrm{pu}$. \\
Machine parameters & $\mathrm{Xd}=1 \mathrm{pu}$, \\
& $\mathrm{Xq}=1 \mathrm{pu}$, \\
& $\mathrm{X}^{\prime} \mathrm{d}=0.18 \mathrm{pu}$, \\
& $\mathrm{T}^{\prime} \mathrm{d} 0=5 \mathrm{~s}$, \\
& $\mathrm{T}^{\prime} \mathrm{q} 0=1.5 \mathrm{~s}$. \\
Voltage regulator parameters & $\mathrm{KA}=30$, \\
& $\mathrm{TA}=0.4 \mathrm{~s}$, \\
& $\mathrm{TE}=0.56 \mathrm{~s}$.
\end{tabular}

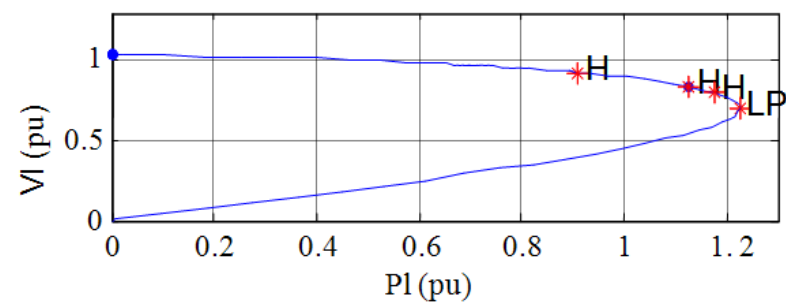

Fig. 3. Continuation of the equilibrium point 


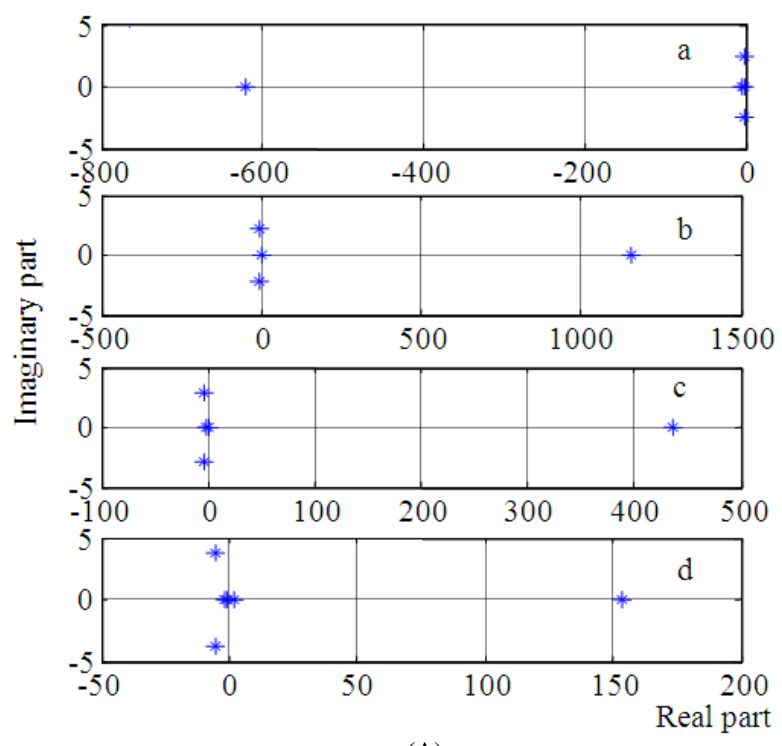

(A)
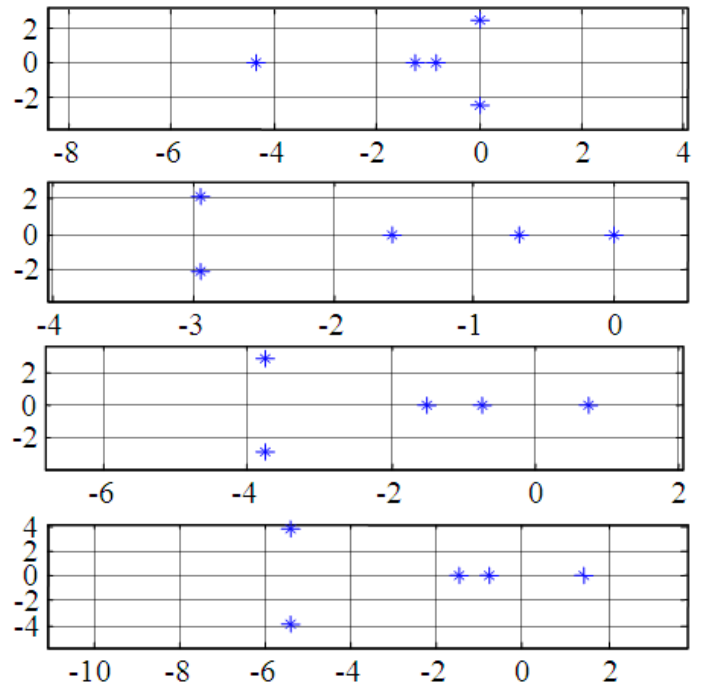

(B)

Fig. 4. (A): Bifurcation at the eigenvalues points. (a) Hopf bifurcation . (b) Limit point bifurcation. (c) neutral saddle point bifurcation1, (d) neutral saddle point bifurcation2. (B): Zoom of (a,b,c,d)

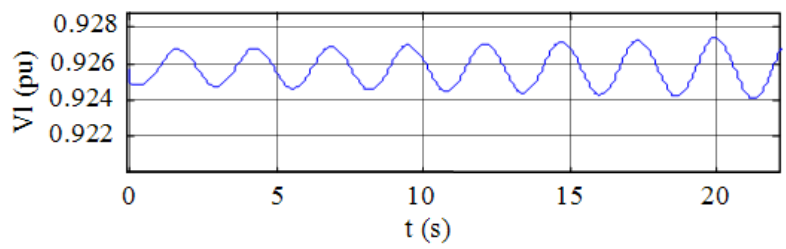

Fig. 5. Reponses time in the Hopf bifurcation point at $\mathrm{Pl}=$ O.91 pu

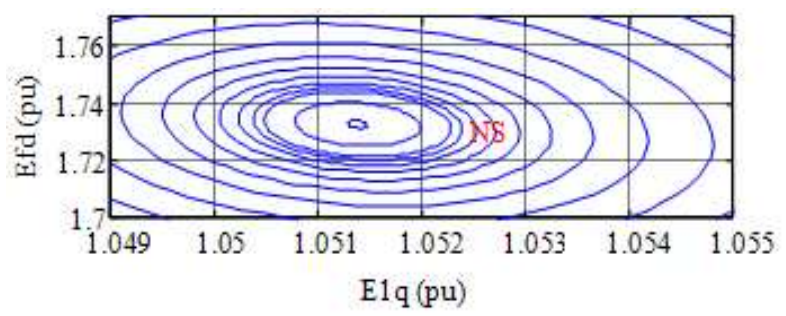

Fig. 6. Excitation voltage versus quadrature transient voltage in the Hopf bifurcation point at $\mathrm{Pl}=\mathrm{O} .91 \mathrm{pu}$

When we simulate the continution in Hopf, we see that the first Lyapunov coefficient $\mathrm{a}=3.212181 \mathrm{e}-001$ is positive indicated that the Hopf bifurcation is subcritical so it generates a limit cycle unstable as shown in Fig. 7 and 8.

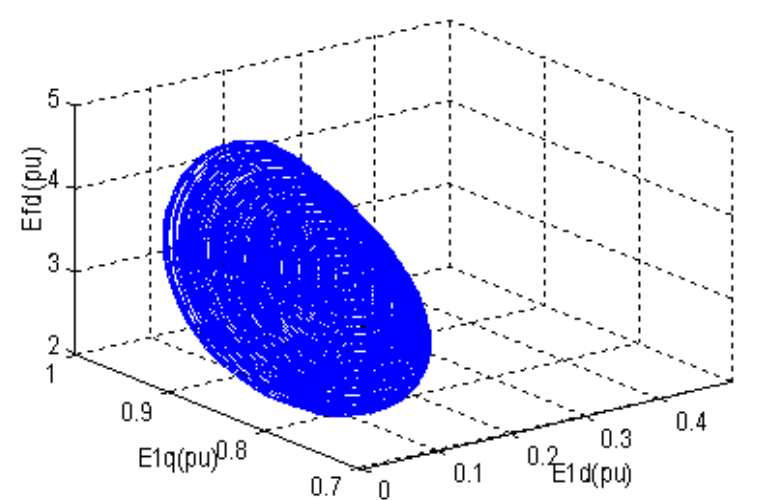

Fig. 7. Continuation of the Hopf point in three axes

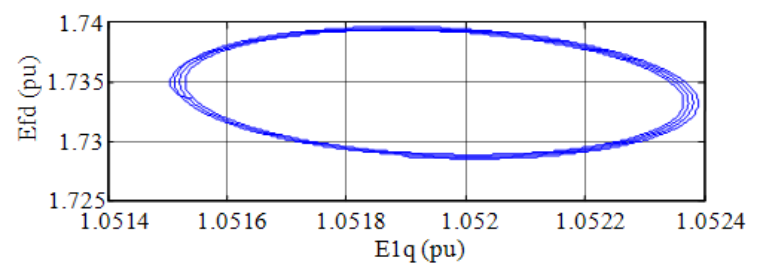

Fig. 8. Continuation of the Hopf point in two axes

\subsection{Continuation of the Limit Point Bifurcation}

We represent the continuation of the limit point with liberate two parameters $\mathrm{Pl}$ and $\mathrm{Ka}$, we found two 
Zero Hopf (labeled by ZH) and a Bagdanov-Taknes (labeled by BT) in Fig. 9 and three Zero Hopf (labeled by $\mathrm{ZH})$ in Fig. 10.

The BT bifurcation is a bifurcation of an equilibrium point in a two parameter family of autonomous ODE at which the critical equilibrium has a zero eigenvalue of algebraic multiplicity (Perez-Londoo et al., 2010).

Figure 9 and 10 represent the continuation of the limit point with liberate two parameters $\mathrm{Pl}$ and $\mathrm{Ka}$ which have as result two Zero Hopf type Neutral Saddle (labeled by $\mathrm{ZH}$ ) at $\mathrm{x}=[0.2462930 .634812$ $\left.\begin{array}{llll}1.149790 & 1.149790 & 0.044223 & 0.496083\end{array}\right]$ with $\mathrm{Pl}=$ 2.089901, the second $\mathrm{ZH}$ is at: $\mathrm{x}=[0.2256130 .567560$

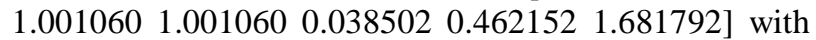
$\mathrm{Pl}=0.275429$ and a Bagdanov-Taknes (labeled by BT)

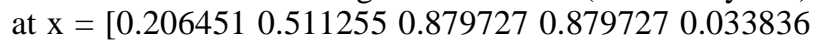
$0.4300071 .384128]$ with $\mathrm{Pl}=0.221489$ and the coefficient $(\mathrm{a}, \mathrm{b})=(2.836047 \mathrm{e}+000,1.764005 \mathrm{e}+001)$.

\subsection{Continuation in Zero Hopf Bifurcation (ZH)}

The Zero Hopf Bifurcation $(\mathrm{ZH})$ is a bifurcation of an equilibrium point in a two parameter family of autonomous ODE at which the critical equilibrium has a zero eigenvalue and a pair of purely imaginary eigenvalues (Perez-Londoo et al., 2010).

In the continuation Zero Hopf, there are two bifurcation point $\mathrm{HH}$ at $\mathrm{x}=\left[\begin{array}{l}0.352036 \\ 0.927452\end{array}\right.$ $1.7106451 .7106450 .0657940 .701325], \mathrm{Pl}=0.734401$ and $\mathrm{x}=\left[\begin{array}{llll}0.392989 & 1.035336 & 1.909621 & 1.909621\end{array}\right.$ 0.073447 0.782913], $\mathrm{Pl}=0.915194$ Fig. 11.

The $\mathrm{HH}$ is the Hamiltonian Hopf bifurcation, the collision of pairs of eigenvalues on the imaginary axis.

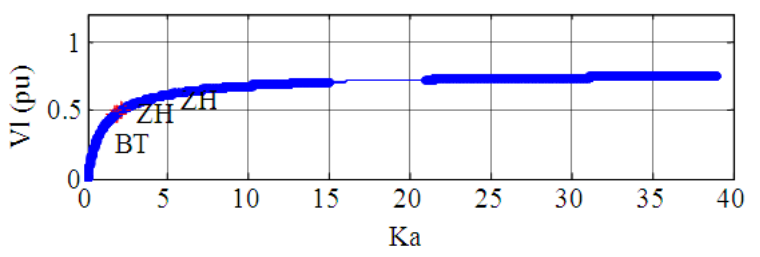

Fig. 9. Continuation of the limit point bifurcation with liberate the parameter $\mathrm{Ka}$

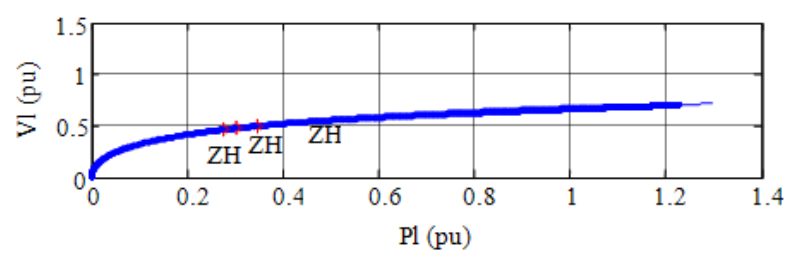

Fig. 10. Continuation in limit point bifurcation with liberate the parameter $\mathrm{Pl}$

\section{DISCUSSION}

In Table 2, the first Lyapunov coefficient a $=$ 3.212181e-001, the Hopf bifurcation is positive implying that there are instability limit cycles bifurcate

We can analyze the distribution of eigenvalues of point bifurcation Table 3. In Hopf point, conjugate eigenvalues purely imaginary. The other points have some positive eigenvalues, so theses points are instable.

We used the matcont package based on continuation method, we arrived to identify the critical voltage and the various bifurcation points and to analyze the behavior of these points in a dynamic power system. That it is difficult with another method of resolution such as Newton-Raphson that is used in a load flow (Acha and Kazemtabrizi, 2010).

Power-voltage curve provides very important information for voltage stability analysis (Kumkratug, 2012), the importance appear in the results found when we analyse the continuation in Hopf, limit point and zero Hopf bifurcation point.

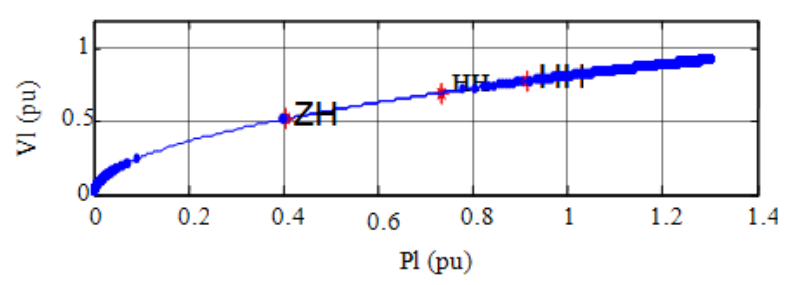

Fig. 11. Continuation in Zero Hopf bifurcation $(\mathrm{ZH})$

Table 2. Bifurcation results

\begin{tabular}{llll}
\hline & $\mathrm{X}$ & $\mathrm{PL}$ & \\
\hline $\mathrm{H}$ & {$[0.430679,1.051378,1.732737$,} & & $\mathrm{a}=3.212181$ \\
& $1.732737,0.066644,0.925803]$ & 0.910066 & $\mathrm{e}-001$ \\
$\mathrm{H}$ & {$[0.425481,1.155084,2.173420$,} & & \\
& $2.173420,0.083593,0.837902]$ & 1.127743 & \\
$\mathrm{H}$ & {$[0.37371 .3112,2.690836$} & & \\
& $2.6908,0.10349,0.70359]$ & 1.177072 & \\
$\mathrm{LP}$ & {$[0.373742,1.311221,2.690836$,} & & $\mathrm{A}=-5.880$ \\
& $2.690836,0.103494,0.703594]$ & 1.226435 & $\mathrm{E}-001$ \\
\hline
\end{tabular}

Table 3. Eigenvalues of the bifurcation points

\begin{tabular}{ll}
\hline $\begin{array}{l}\text { Point } \\
\text { bifurcation }\end{array}$ & Eigenvalues \\
\hline $\mathrm{H}$ & $-622.1,-4.3429,-1.24882,-0.8201$, \\
& $-1.8537 \mathrm{e}-008+2.43913,-1.8537 \mathrm{e}-008-2.43913$ \\
$\mathrm{H}$ & $-5.4235+3.8268,-5.4235-3.8268,-1.4557$, \\
& $-0.77209,1.4557,153.918$ \\
$\mathrm{H}$ & $-3.7495+2.9168,-3.7495-2.9168,-1.5010$, \\
& $0.7533,437.102$ \\
LP & $-2.9455+2.1289,-2.9455-2.1289,-1.5726$, \\
& $-0.6830,-4.5715 \mathrm{e}-008,1160.12$ \\
\hline
\end{tabular}




\section{CONCLUSION}

In this study we study the dynamics of a two-node power system and we found many dynamical bifurcation, including the Hopf bifurcation, zero Hopf bifurcation, Hamiltonian-Hopf bifurcation, Bogdanovtakens bifurcation, limit point bifurcation and saddle node bifurcatio. We also observed and investigated the stability of Limit cycles generated by the continuation of the Hopf bifurcation point by examining the sign of first Lyapunov coefficient and the continuation of the Limit Point Bifurcation with liberate two parameters $\mathrm{Pl}$ and $\mathrm{Ka}$.

A future work will be a study of a dynamic power system with several node. Such as nine bus power system model, we will use the standard contuniation package matcont and we will know the other type of bifurcation points.

\section{REFERENCES}

Abro, A.G. and J. Mohamad-Saleh, 2012. Control of power system stability reviewed solutions based on intelligent systems. Int. J. Innov. Comput. Inform. Control, 8: 6643-6666.

Acha, E. and B. Kazemtabrizi, 2010. A new STATCOM model for power flows using the newton-raphson method. IEEE Trans. Power Syst., 28: 2455-2465. DOI: $10.1109 /$ TPWRS.2012.2237186

Avalos, R.J., C.A. Canizares, F. Milano and A.J. Conejo, 2009. Equivalency of continuation and optimization methods to determine saddle-node and limit-induced bifurcations in power systems. IEEE Trans. Circ. Syst., 56: 210-223. DOI: 10.1007/s11071-008-9398-3

Echavarren, F.M., E. Lobato and L. Rouco, 2009. Steady-state analysis of the effect of reactive generation limits in voltage stability. Electr. Power Syst. Res., 79: 1292-1299. DOI: 10.1016/j.epsr.2009. 03.006

Fang, Y. and H.G. Yang, 2012. Saddle-node bifurcation of power systems analysis in the simplest normal form. Proceedings of the International Conference on Computer Distributed Control and Intelligent Enviromental Monitoring, Mar. 5-6, IEEE Xplore Press, Hunan, pp: 613-616. DOI: 10.1109/CDCIEM.2012.151.
Ghaffari, A., M. Tomizuka and R.A. Soltan, 2009. The stability of limit cycles in nonlinear systems. Nonlinear Dyn, 56: 269-275. DOI: 10.1007/s11071008-9398-3

Govaerts, W., Y.A. Kuznetsov and A. Dhooge, 2005. Numerical continuation of bifurcations of limit cycles in MATLAB. J. Sci. Comput., 27: 231-252. DOI: 10.1137/030600746

Jazaeri, M. and M. Khatibi, 2008. A study on Hopf bifurcations for power system stability analysis. Proceedings of the IEEE Canada Electric Power Conference, Oct. 6-7, IEEE Xplore Press, Vancouver, BC., pp: 1-6. DOI: 10.1109/EPC.2008.4763323

JiaKuan, X. and M. Xin, 2007. Bifurcation analysis for power system voltage stability based on singular perturbation method. Proceedings of the Electrical Machines and Systems. ICEMS. International Conference on, Seoul, Korea, Oct. 8-11, IEEE Xplore Press, pp: 1811-1814. DOI: 10.1007/s11071008-9398-3

Kumkratug, P., 2012. Power-voltage characteristics of power system with the medium transmission line. Am. J. Applied Sci., 9: 886-889. DOI: 10.3844/ajassp.2012.886.889

Perez-Londoo, S., G. Olivar and J. Mora-Florez, 2010. Zero-Hopf bifurcation analysis on power system dynamic stability. Proceedings of the IEEE/PES Transmission and Distribution Conference and Exposition: Latin America, Nov. 8-10, IEEE Xplore Press, Sao Paulo, pp: 765-769. DOI: 10.1109/TDCLA.2010.5762970

Subramani, C., S.S. Dash, V. Kumar and H. Kiran, 2012. Implementation of line stability index for contingency analysis and screening in power systems. J. Comput. Sci., 8: 585-590. DOI: 10.3844/jcssp.2012.585.590 